\title{
KINETIC STUDY ON SYNTHESIS OF BIODIESEL FROM WASTE COOKING OIL USING FLY ASH/KNO ${ }_{3}$ CATALYST
}

\section{RAJAMBHUKYA}

Department of Chemical Engineering, University College of Technology, Osmania University, Hyderabad, Telangana, India

Received: Jun 06, 2020; Accepted: Jun 26, 2020; Published: Aug 07, 2020; Paper Id.: IJMPERDJUN2020677

\section{INTRODUCTION}

There are many issues associated with the application of the petroleum based fuels. Higher depletion rates of resources, increased cost for production, increased pollution problems are some of them. All these features are motivating the technologists to search for the alternative renewable fuels [1]. On the other hand, huge quantities of animal fats and waste cooking oils (WCO) are abundantly available and managing of such fats and oils is a very significant challenge due to their disposal problems. The used vegetable oil, it is other way called as waste cooking oil, is one of the best cost-effective options to harvest biodiesel. Subsequently, one of the major concerns for the manufacture of biodiesel is the cost of feedstock; use of WCO considerably increases the economic feasibility of biodiesel manufacture [2]. Transesterification with a catalyst is the reaction of oil with an alcohol $(\mathrm{ROH}, \mathrm{R}=\mathrm{CH} 3$ or $\mathrm{C} 2 \mathrm{H} 5$ and etc.) and a catalyst to produce esters and glycerol [3]. Methanol is basically employed due to low cost, physical and chemical advantages such as polar and smallest chain alcohol. Transesterification can happen depending on the oil at different temperatures. On the other hand, a higher temperature apparently affects the reaction rate and ester's yield. The product of the transesterification reaction contains primarily of esters, glycerol, and traces of alcohol, catalyst, triglycerides, Diglycerides, and Monoglycerides [4]. Among the methods, transesterification is the best adoptable process, which is an organic process in which an ester is transformed into 
the alkoxy molecule. The chemical reaction is shown in Scheme (I).<smiles>[R]OCC(CO[2H])OC([R])O</smiles>

Triglyceride<smiles>C#CCOC</smiles>$$
\mathrm{HO}
$$<smiles>[R]C(=O)OC</smiles>

Glycerol
(I)

\section{Methyl Esters}

Also, the preparation of catalysts of heterogeneous from waste materials has been becoming progressively more popular from the last two decades. Some of the most interesting resources are waste biomass from agriculture such as inedible oils, animal waste and Flyash [5]. Application of waste materials is highly advantageous in view of financial or conservation costs accompanying with their discarding. The problems involved with homogeneous catalysts such as removal of costly catalysts, separation of products, longer operational time will be rightly answered by heterogeneous catalysts. Unlike to homogeneous catalysts, solid heterogeneous catalysts have the advantages of ease of separation from the reaction mixture after the reaction completed and ease of regeneration of the material for reuse [6].The main objective of present paper is to develop the heterogeneous catalysts from solid waste materials such as flyash and to study the performance of the heterogeneous catalyst towards the biodiesel synthesis from WCO.

\section{MATERIALS AND METHODOLOGY}

The catalyst is prepared from solid waste material such as fly ash obtained from Thermal Power Plant (NTPC). The materials were collected from where they were available at low cost or zero cost. The solvents and reagents used for the preparation of solid catalysts and for reaction studies were A. R. grade (99.9\%). The solvents and reagents were procured from M/S Sd Fine- Chem Limited, Mumbai, India.

\section{Method of Catalyst Preparation}

Fly ash is a product of coal and contains fine particles. In modern coal based power plants, fly ash is usually prevented by electrostatic precipitators (ESP) or other particle filtration equipment like bag filters after the flue gases reach the chimneys. The composition of fly ash could differ significantly depending upon the source of the coal where it burned. Mostly, the fly ash includes considerable amounts of silicon dioxide ( $\mathrm{SiO} 2$ ) (both amorphous and crystalline), aluminum oxide (A12O3), calcium oxide $(\mathrm{CaO})$ and etc. Various methods were developed to prepare catalysts using fly ash. Wet impregnation method was adopted to prepare the solid catalyst from solid waste materials. In this, for 10gm of fly ash dry sample, $10.2 \mathrm{~mL}$ of $1 \mathrm{~N}$ aqueous solution of potassium nitrate is added slowly with constant manual stirring until the homogeneous mixture is attained. Then, the excess water is driven off using the rotary evaporator. After drying at $100 \mathrm{oC}$ till complete removal of water, the solid mixture is calcined at a temperature of $500{ }^{\circ} \mathrm{C}$ for $5 \mathrm{~h}$ in an ambient air flow. The obtained dry fly ash-KNO3 catalyst powder was characterized by XRD, SEM and FTIR technics. The prepared fly ashKNO3 catalyst powder was directly used for the production of biodiesel from WCO. The high temperature furnace was used to prepare fly ash-KNO3 catalyst. The high temperature furnace was shown in Figure (2). The fly ash powder used as received condition for synthesis the catalyst and after heat treatment condition (fly ash-KNO3 catalyst) was shown in Figure(3). 


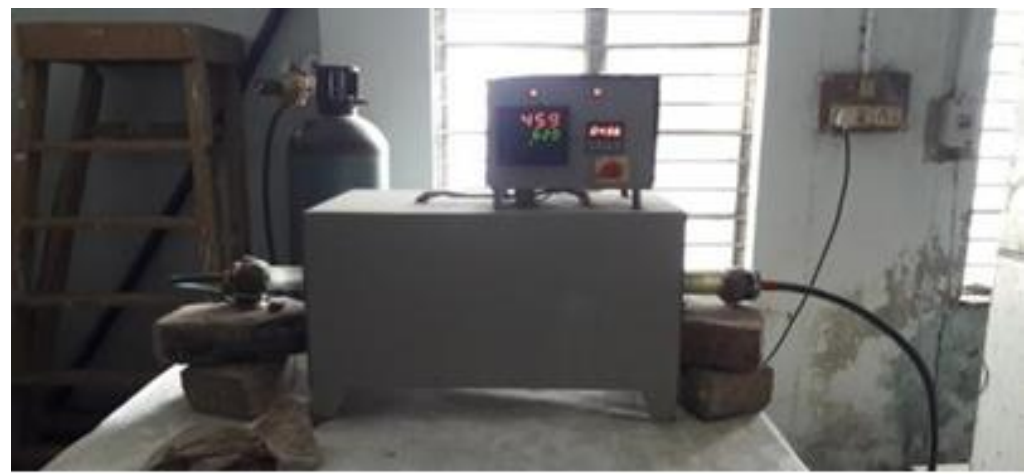

Figure 2: High Temperature Furnace used to Prepare Fly Ash Catalysts.
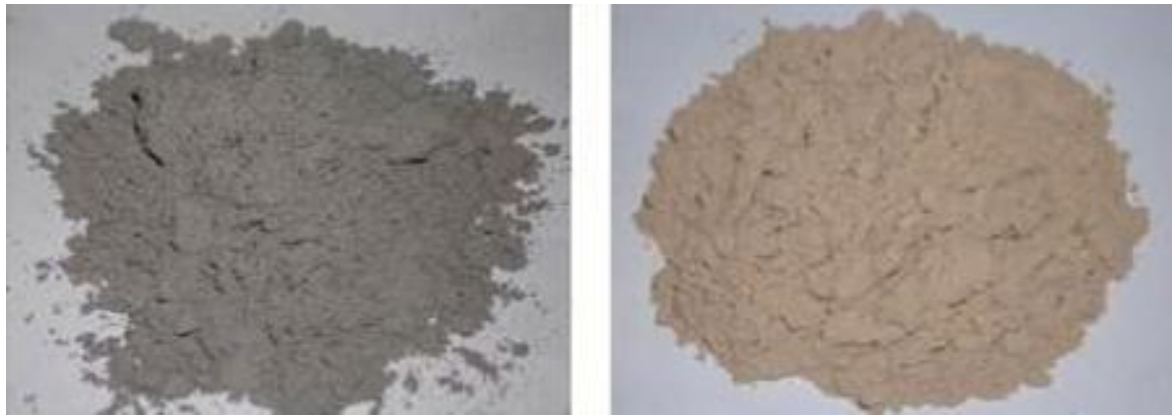

Figure 3: The Fly Ash used for Synthesis (a) as it is Received Condition and (b) After Heat Treatment Condition (Flyash-KNO${ }_{3}$ ).

\section{Characterization of Catalysts}

The primary objective of catalyst characterization is to study the relationship among physical and chemical properties as well as its activity. It is important for designing and a process optimization. The characterization is required and necessary to observe the variations in chemical and physical properties of a catalyst in the course of preparation, activation and reaction steps for well understanding and control of quality. The prepared catalyst is characterized by XRD, SEM and FTIR. The prepared samples were analyzed by a Siemens $500 \mathrm{X}$ - ray powder diffract meter in a flat plane geometry with a source of $\mathrm{Cu}-\mathrm{K} \alpha$ of wavelength,

$1.5406 \AA$. The XRD spectra were recorded in the region of $10-80 \mathrm{o}(2 \theta)$ in steps of 0.0010 with a counting time of $1 \mathrm{~s}$ in each step. The specifications of the instruments for the XRD analysis are given in Table 1.

Table 1: Measurement Conditions

\begin{tabular}{|c|c|}
\hline X-Ray Tube of Target & $\mathrm{Cu}-\mathrm{K} \alpha$ \\
\hline Voltage & $40 \mathrm{KV}$ \\
\hline Current & $30.0 \mathrm{~mA}$ \\
\hline \multicolumn{2}{|c|}{ Slits } \\
\hline Divergence slit & $1.0^{\mathrm{O}}$ \\
\hline Scatter slit & $10.0^{\mathrm{O}}$ \\
\hline Receiving slit & $0.3 \mathrm{~mm}$ \\
\hline Scanning & $\theta-2 \theta$ \\
\hline Scan range & $10.0-80.0^{\mathrm{O}}$ \\
\hline Scan mode & continuous scan \\
\hline Scan speed & 2.0 degree/min \\
\hline sample pitch & 0.02 degree \\
\hline Present time & $0.6 \mathrm{sec}$ \\
\hline
\end{tabular}


The powder XRD patterns of fly ash-KNO3 catalyst were presented in the Figure 4. The compound exhibited the characteristic peaks of crystalline phases such as silica $(\mathrm{SiO} 2)$, calcium carbonate $(\mathrm{CaCO} 3)$, alumina $(\mathrm{Al} 2 \mathrm{O} 3)$ and iron oxide (Fe2O3). The predominant phase was quartz ( $\mathrm{SiO} 2)$ with main peak at $23.16^{\circ}(2 \theta)$ and other peaks of $\mathrm{CaCO}$, $\mathrm{Al} 2 \mathrm{O} 3$ and $\mathrm{Fe} 2 \mathrm{O} 3$ were identified as shown in the Figure 4. From the XRD result of fly ash-KNO3 catalysts, it has the crystalline phases of quartz, magnetite and mullite. The hematite peak was not found due to the high concentration of magnetite.

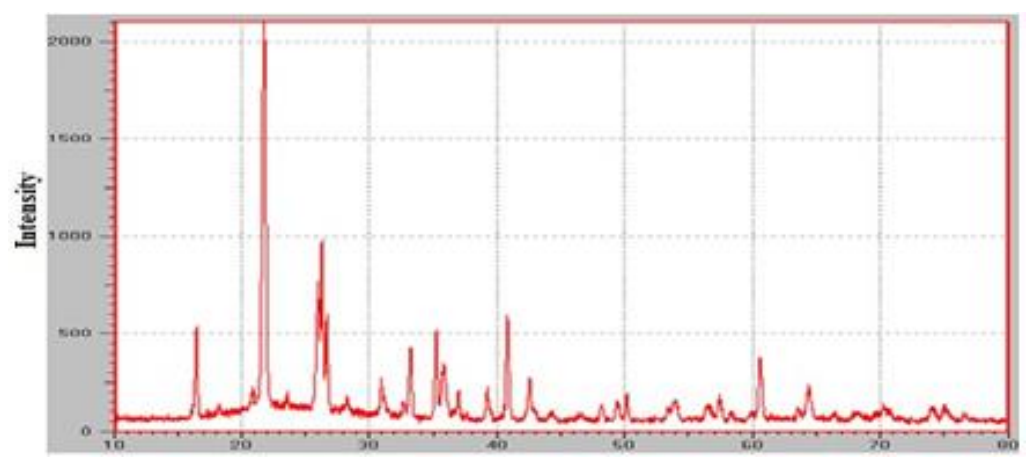

Figure 4: XRD Graph of Fly ash-KNO 3 Catalyst.

\section{SEM Analysis}

SEM is useful in obtaining morphology of the unknown components. The morphology of the fly ash-KNO3, egg shell and sodium bentonite catalysts synthesized in the present work was examined by using a Hitachi X-650 scanning electron microscope (SEM) analyzer equipped with a CDU lead detector at $25 \mathrm{kV}$. The prepared samples were placed on aluminum pegs and coated with a gold thin film to allow them conductive. The SEM scans with a focused electron beam onto a surface to produce an image. The electrons from the beam interact with the prepared sample, generating a number of signals that can be used to attain images about the surface morphology. The SEM can produce three-dimensional images. The resolution is $0.2 \mathrm{~nm}$ which is 1000 times more than a light microscope. A typical SEM photograph of fly ash-KNO3 catalyst is shown in the Figures 5 and 6. It shows the irregular morphology of fly ash-KNO3. It provides three dimensional data on an atomic or near atomic scale for varying resolutions of 500, 100, 50 and $10 \mu \mathrm{m}$.

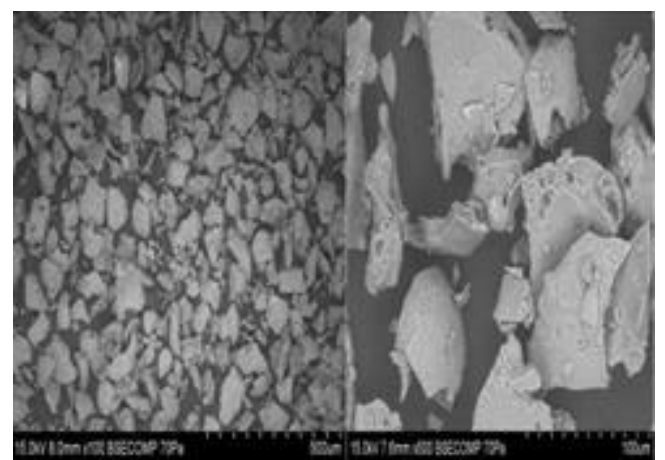

Figure 5: SEM Photographs of Fly ash-KNO 3 Catalyst with 500 and $100 \mu \mathrm{m}$ Resolutions. 


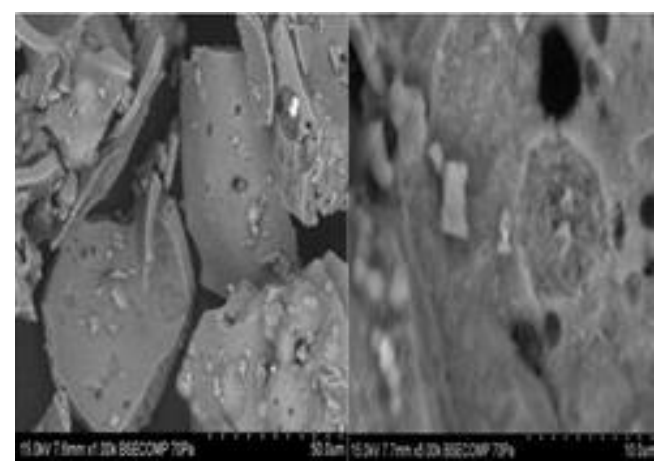

Figure 6: SEM Photographs of Fly Ash-KNO 3 Catalyst with 50 and $10 \mu \mathrm{m}$ Resolutions.

\section{Fourier Transform Infrared Spectroscopy (FT-IR)}

The FT-IR was used to study the changes in a material and also give data about the functional of a sample. It requires practically sample preparation with potassium bromide as a pellet. However, around $15 \mathrm{mg}$ of the prepared catalysts sample is employed in the attenuated total reflectance (ATR) sample holder of a Perkin Elmer Spectrum 100 FT-IR spectrometer. The samples were recorded in the range of 4000-400 cm-1, baseline was corrected and the spectra were smoothened. The FTIR bands from 900 to $1200 \mathrm{~cm}-1$ were recognized as various types of Si-O and Si-O-Si stretching vibrations. The other bands between 450 and $900 \mathrm{~cm}-1$ in the spectra of fly ash-KNO3 were gave the typical Si-O and $\mathrm{Si}-$ $\mathrm{O}-\mathrm{Al}$ bending modes. The FTIR pattern of fly ash-KNO3 catalyst is shown in Figure7.

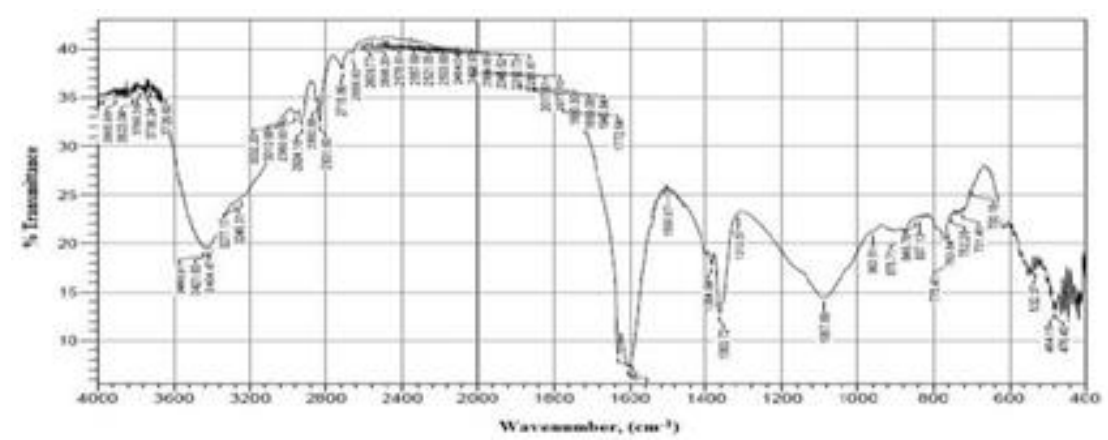

Figure 7: FT-IR Patterns of Fly Ash-KNO 3 Catalyst.

\section{EXPERIMENTAL}

The prepared heterogeneous catalyst is used for the production of biodiesel from WCO. It has a series of three sequential reversible reactions where triglycerides (TGs) are converted to diglycerides (DGs) and DGs are converted to monoglycerides (MGs) and MGs are converted to glycerol. In each step an ester is formed and thus three ester molecules are generated from one molecule of TG. At the initial stage of the reaction, there is a need of vigorous mixing of oil. So, the oil and the methanol get uniformly mixed. However, as the process results the formation of the product, slight mixing is required to facilitate the settling down of glycerol, so that reactions can continue in the upper layer of methanol and oil. The stoichiometry of transesterification of triglyceride (WCO) with methanol was shown in Scheme (I). The stoichiometric relation between the oil and the alcohol is 1:3. However, an additional use of alcohol is generally more suitable to increase the reaction in the direction of the desired product.

The transesterification reaction is accelerated by a catalyst. Various types of catalysts including homogeneous (such as $\mathrm{HCl}, \mathrm{H} 2 \mathrm{SO} 4$ ) [7] or heterogeneous catalysts (metal based catalysts like Zeolite supported alumina) are employed 
for the process. The advantages of heterogeneous catalysts like ease of separation of products attracting the researchers to go with heterogeneous catalysis. As the reaction is reversible in nature excess alcohol is used to shift the reaction towards the products. Flyash catalytic performance is studied in synthesis of biodiesel from WCO. All the experiments were performed at atmospheric pressure and the effect of several variables were studied on the conversion of WCO to biodiesel. The different parameters and their range used in the experiments were given in Table 2.

Table 2: List of Different Parameters and Their Range in The Experiments

\begin{tabular}{|l|c|}
\hline \multicolumn{1}{|c|}{ Parameters } & Range \\
\hline Temperature & 40,50 and $60{ }^{\circ} \mathrm{C}$ \\
\hline Mole Ratio (Alcohol to WCO) & $6: 1,9: 1$ and $12: 1$ \\
\hline Catalyst Loading (\% of reaction mixture weight) & $0.5,1.0$ and 1.5 \\
\hline
\end{tabular}

\section{Experimental Procedure and Process Description}

A REMI make magnetic stirrer, heating mantle assembly was used to carry out the reaction and a 1 liter 3-neck round bottom flask equipped with a water-cooled reflux condenser at the center neck will act as reactor. One neck of the flask was provided with a thermal well \& thermometer while the other neck is closed with a dummy cap, through which reactants are introduced and mid reaction samples can be collected. The entire apparatus was placed in an oil bath to maintain the reaction temperatures with $+/-2^{\circ} \mathrm{Caccuracy}$.

In a typical run, Certain amount of Waste cooking oil (WCO) and Calculated amount of catalyst was taken in the RB Flask where the contents were heated to $60^{\circ} \mathrm{C}$ gradually Continuous supply of RT water was arranged across the reflux condenser. At the instance of attaining the pre-specified temperature, Specified amount of methanol was introduced to the Flask and the instant was read as time ' $t=0$ '. The entire process was carried in contact with air at ambient pressure. The reaction was allowed to proceed continuously and at regular interval of 15 minutes, the stirrer was switched off, the contents allowed to settle for 2 minutes, and $5 \mathrm{ml}$ of reaction mixture was collected from top layer using a pipette. The sample was collected carefully so that neither bottom layer nor catalyst pellets are present in the sample. The sample was transferred to an ice chamber with an addition of $5 \mathrm{ml}$ of isopropyl alcohol and analyzed. The reaction was continued till the two consecutive readings are attained. The reaction apparatus and the reaction mixture are shown in Figure 8.(a) and (b).

After completion of the reaction, the mixture was transferred to a separating funnel, allowed to demarcate into two layers as shown in Figure 9. with the top layer (bio diesel layer) recovered, analyzed Figure 10. and the residual methanol separated via rotary evaporation. Data was collected to study the effect of the various parameters such as Temperature, Mole Ratio, and CatalystLoading.

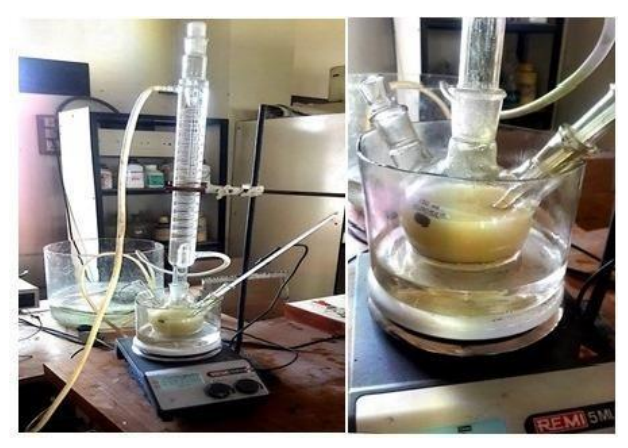

Figure 8: Experimental Setup for Biodiesel Synthesis from WCO. 


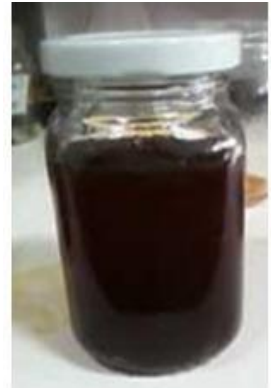

(a)

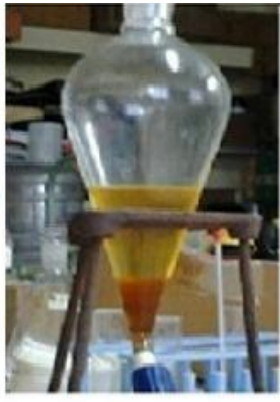

(b)

Figure 9: (a) Waste Cooking Oil, (b) Formation of Two Layers of the Reaction Mixture in the Biodiesel Production Process.

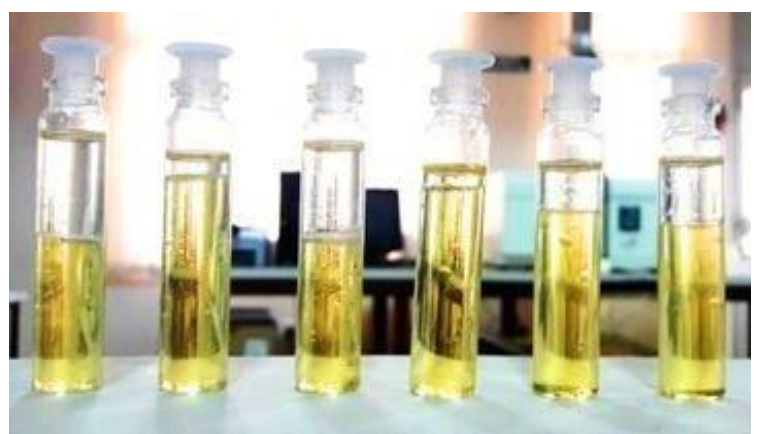

Figure 10: Samples of the Reaction Mixture Collected at Different Time Intervals. (15- 90 min).

Table 3: Composition of Waste Cooking Oil from Sunflower Oil

\begin{tabular}{|l|c|c|}
\hline \multicolumn{1}{|c|}{ Fatty Acid Compound } & Molecular Formula & (\%) Composition \\
\hline Stearic & $\mathrm{C}_{18} \mathrm{H}_{36} \mathrm{O}_{2}$ & 6.7 \\
\hline Oelic & $\mathrm{C}_{18} \mathrm{H}_{34} \mathrm{O}_{2}$ & 25.2 \\
\hline Linoleic & $\mathrm{C}_{18} \mathrm{H}_{32} \mathrm{O}_{2}$ & 66.8 \\
\hline Eicosanioc & $\mathrm{C}_{2} 0 \mathrm{H}_{40} \mathrm{O}_{2}$ & 1.3 \\
\hline
\end{tabular}

After completion of the reaction, the reaction mixture was shifted to a separating funnel and permitted to separate in to the two layers. The top layer (biodiesel layer) was recovered and analyzed. The remaining methanol was removed by using rotary evaporation system. Data was collected to determine the conversion of WCO. The experiments were performed to study the effect of various parameters for example temperature, molar ratio and loading of a catalyst. Formation of two layers of the reaction mixture in the biodiesel production process was shown in Figure 9. The reaction mixture samples were collected at different time intervals was shown in Figure 10.

\section{RESULTS AND DISCUSSIONS}

Effect of the catalysts prepared for transesterification of waste cooking oil (WCO) are studied experimentally in a laboratory batch reactor. The experimental data was analyzed to find out the effect of temperature, mole ratio and catalyst loadings. The optimum ranges of the parameters are analyzed in the study the effects of the various parameters over the progress of reaction/conversion were studied, data collected and the results were analyzed. 


\section{Effect of Temperature}

Since the rate constant is a strong function of temperature, its effect over the progress of the reaction requires careful study. To determine the optimum operating temperature, Trans-esterification reaction was conducted with differential methanolwaste cooking oil mole ratios and three different catalysts loadings.

As indicated in the Figure11.the percentage conversion of waste cooking oil was less at lower temperatures and was increased with the temperature. For all the three catalysts, with increment in temperature from 40 to $60^{\circ} \mathrm{C}$, a corresponding increase in the WCO conversion was observed and beyond to $60^{\circ} \mathrm{C}$, there is fractional decrement in the conversion. This is probably due to the boiling point of methanol, which is around $64.7^{\circ} \mathrm{C}$ and the reaction above to boiling point temperature might cause methanol to vaporize into gaseous state causing low catalytic activity. Moreover, higher temperatures would increase the saponification. Thus the reaction operating temperature was limited to $60^{\circ} \mathrm{C}$ for the transesterification of waste cooking oil studies. The maximum conversion attained in the process is $83.4 \%$ with theKNO $3 / \mathrm{Fly}$ Ash catalyst at $60^{\circ} \mathrm{C}$ with mole ratio9.

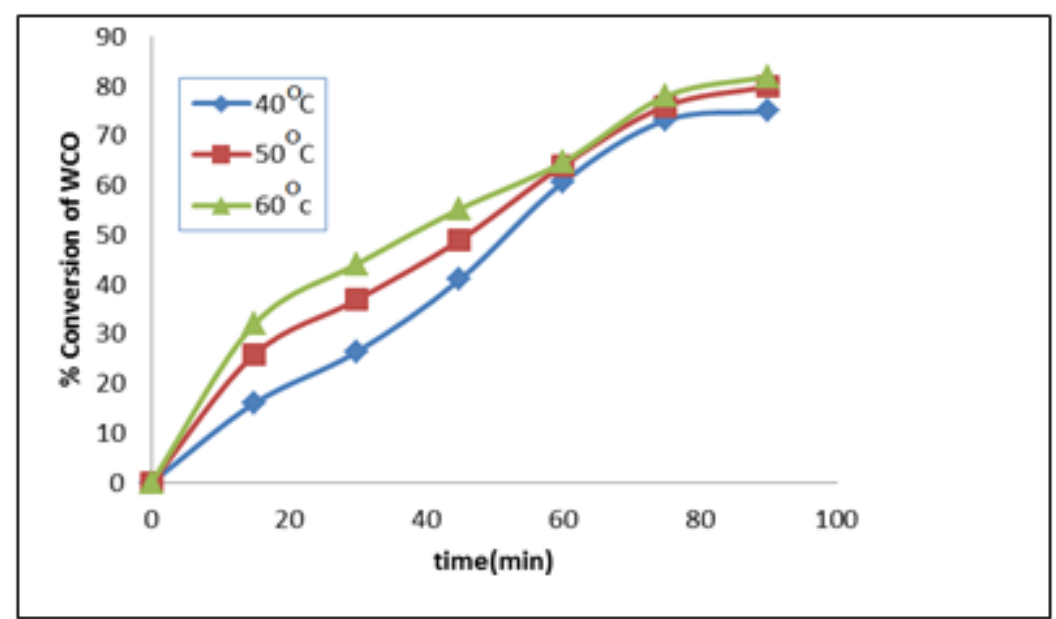

Figure 11: Effect of Temperature on the Conversion of WCO with the $\mathrm{KNO}_{3} / \mathrm{Fly}$ Ash Catalyst for Mole Ratio 9 and Catalyst Loading $1 \%$.

\section{Effect of Methanol -WCO Moleratio}

One of the most important factors that affect the yield of ester is the molar ratio of alcohol to waste cooking oil and this is the parameter, which is crucial for screening the catalyst performance. Although the stoichiometric molar ratio of Methanol to Triglycerides for trans-esterification is 3, higher molar ratios are used to enhance the solubility and increase the contact between the oil and alcohol molecules. Specifically, it has also been proven that the use of excess alcohol is a suitable mode of improving the rate of the trans-esterification reaction where heterogeneous catalysts are utilized.

The effect of the molar ratio of reactants was examined with the one catalyst and varying catalyst loadings. Figure 12.represent the cases of percentage conversions of WCO with 1.0\% KNO3/Fly Ash catalyst respectively. From the plot, it can observe that with increasing the mole ratios of reactants, the conversion increases, but with decreasing rates. 


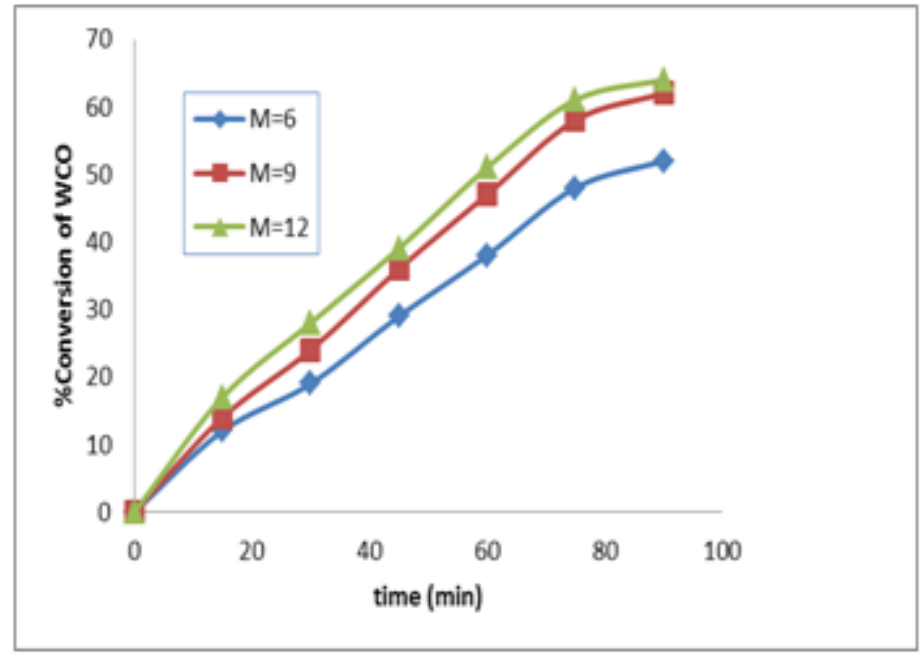

Figure 12: Effect of Mole Ratio on the Conversion of WCO for 1.0\% Loading of $\mathrm{KNO}_{3} / \mathrm{Fly}$ Ash Catalyst at $600 \mathrm{C}$.

From the above plot, it was observed that at the mole ratios beyond to 9 , there is no much increment in the conversion terms; the higher mole ratio of methanol than the stoichiometry requirement also results in higher unconverted reactant, i.e; alcohol and recovery of the compound will be another economic aspect to account for. From these aspects, it was proposed to operate the systems at the mole ratio of ' 9 .

\section{Effect of Catalyst Loading}

From the view point of the reaction kinetics, using more catalyst leads to higher yield of esters in a shorter time. In the reaction, three levels of catalyst loadings (wt \%) are tested i.e., $0.5 \%, 1.0 \%$ and $1.5 \%$ of total reaction mixture for the one catalyst that are considered. The observations are presented in the figure13. For the temperature of $60^{\circ} \mathrm{C}$ and mole ratio 9.

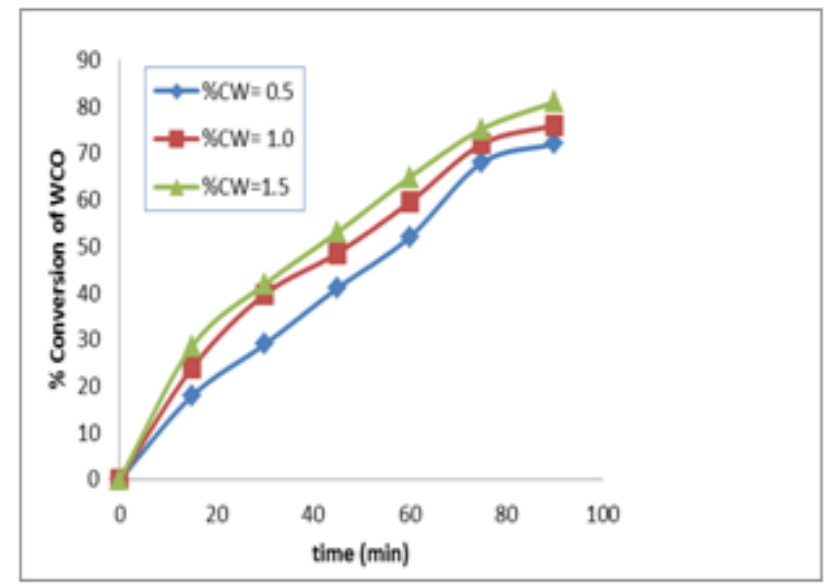
Figure 13: Effect of Catalyst Loading on the Conversion of WCO with
KNO3/Fly Ash Catalyst at $600 \mathrm{C}$ and Mole Ratio 9.

From the plot, it can be observed that, with increasing the catalyst loading, the conversion are increasing gradually for At the higher reaction times, the two loadings of the catalysts $1.0 \%$ and $1.5 \%$ yield similar levels of conversions. For the $1.5 \mathrm{wt} \%$ catalyst loading, the above study indicates with $1.5 \mathrm{wt} \%$ loading attains conversion $83.4 \%$. 


\section{Kinetic Studies}

Kinetic analysis is one of the important aspect of any chemical reaction, that provides represents the qualitative and quantitative accounts of the process. In the present work the experimental data analyzed with the knowledge of the reaction engineering. The Trans-esterification of waste cooking oil with methanol in the present study are analyzed and found the pseudo first order kinetics are applicable in terms of the limiting reactant. The analysis of the experimental data for the reaction systems are presented in the following sections.

\section{Kinetic Parameters Estimation for the Trans-Esterification of Waste Cooking Oil Reaction}

The representative stoichiometric equation for the trans-esterification of waste cooking oil with methanol is presented in Figure 1. As per the stoichiometry, three moles of methanol is necessary to carry out the reaction, whereas the different moles of methanol were considered for the study is 6,9 and 12. As the reaction runs were carried with excess of methanol, the kinetics of the reaction satisfies the pseudo first order in terms of the limiting reactant, i.e; waste cooking oil (WCO).

\section{Study of $\mathrm{KNO}_{3} / \mathrm{Fly}_{\text {Ash Catalyst }}$}

Trans-esterification reaction was carried using $\mathrm{KNO}_{3} / \mathrm{Fly}$ Ash catalysts with the varied loadings. Effect of various parameters such as Temperature, Catalyst weight $(\% \mathrm{CW})$ and mole ratio of the reactants are presented in the previous chapters. From the experimental analysis, mole ratio of 9 with catalyst loading $1.5 \%$ of the total reaction mixture results in the higher conversion levels of the Waste cooking oil at $60^{\circ} \mathrm{C}$. The feed conditions and the analyzed experimental data of the reaction is presented in the table 4 and 5

Table 4: Feed Conditions for Trans esterification of Waste Cooking Oil with $\mathrm{KNO}_{3} / \mathrm{Fly}$ Ash Catalyst

\begin{tabular}{|c|c|c|c|c|c|}
\hline $\begin{array}{c}\text { Transesterification } \\
\text { Catalyst }\end{array}$ & $\begin{array}{c}\text { Catalyst weight, } \\
(\boldsymbol{\%} \mathbf{C W}), \mathbf{g}\end{array}$ & $\begin{array}{c}\text { Reaction } \\
\text { temperature, (T), } \\
{ }^{\mathbf{0}} \mathbf{C}\end{array}$ & $\begin{array}{c}\text { Waste Cooking } \\
\text { Oil,(WCO) }\end{array}$ & $\begin{array}{c}\text { Methanol } \\
\text { moles }\end{array}$ & $\begin{array}{c}\text { Methanol - } \\
\text { Oil ratio, (M) }\end{array}$ \\
\hline $\mathrm{KNO}_{3} /$ Fly Ash & 1.5 & 60 & 1 & 9 & 9 \\
\hline
\end{tabular}

\begin{tabular}{|c|c|c|c|c|c|c|c|}
\hline \multicolumn{7}{|c|}{ Table 5: Experimental Data Analysis for Trans esterification of Waste Cooking Oil } \\
\hline $\begin{array}{c}\text { Reaction } \\
\text { Time }\end{array}$ & $\begin{array}{c}\text { WCO } \\
\text { (Mole) }\end{array}$ & $\begin{array}{c}\text { Methanol } \\
\text { (Mole) }\end{array}$ & $\begin{array}{c}\text { Linolic } \\
\text { Acid }\end{array}$ & Olic Acid & Bio Diesel & $\begin{array}{c}\text { Glycerol } \\
\text { (Mole) }\end{array}$ & $\begin{array}{c}\text { \% Conversion of } \\
\text { WCO, }\end{array}$ \\
\hline $\mathrm{t},(\mathrm{min})$ & & & $($ mole $)$ & $($ mole) & $($ mole $)$ & & $(\%$ XWCO) \\
\hline 0 & 0 & 0 & 0 & 0 & 0 & 0 & 0 \\
\hline 15 & 0.7135 & 8.065 & 0.2675 & 0.5745 & 0.842 & 0.2657 & 28.7 \\
\hline 30 & 0.5811 & 7.974 & 0.3873 & 0.7845 & 1.1718 & 0.3765 & 41.9 \\
\hline 45 & 0.4927 & 7.453 & 0.5278 & 0.8954 & 1.4232 & 0.5437 & 50.7 \\
\hline 60 & 0.3517 & 7.244 & 0.634 & 1.155 & 1.789 & 0.6754 & 64.8 \\
\hline 75 & 0.2478 & 6.874 & 0.7526 & 1.356 & 2.1086 & 0.7824 & 75.2 \\
\hline 90 & 0.1657 & 5.986 & 0.8653 & 1.645 & 2.5103 & 0.8954 & 83.4 \\
\hline
\end{tabular}

A plot of $-\ln \left(1-X_{A}\right)$ vs time was drawn for the three temperatures, which is shown in figure 17. All the plots are linear with the value of $\mathrm{R}^{2}$ is in the order above to 0.95 . The rate constants of the reaction at the three different temperatures are also read from the graph, which are $0.0148 / \mathrm{min}, 0.0187 / \mathrm{min}$ and $0.0193 / \mathrm{min}$ corresponding to 40,50 and $60^{\circ} \mathrm{C}$ respectively. The $\mathrm{k}$ values are tabulated in the Table 6.and Arrhenius plot was drawn for the reaction which is shown in figure17. 


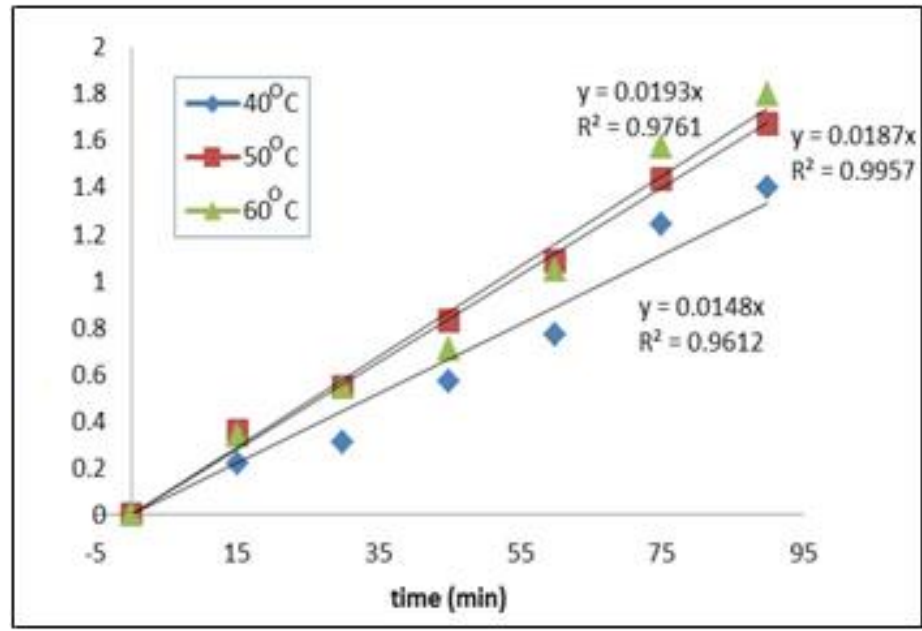

Figure 17: Plot of -In(1-XA) vs Time Drawn for $\mathrm{KNO}_{3} / \mathrm{Fly}$ Ash Catalyst of 1.5\% Loading and Mole Ratio 9.

Table 6: Ink vs (1/T) Data for the $\mathrm{KNO}_{3} / \mathrm{Fly}$ Ash Catalyst.

\begin{tabular}{|c|c|c|c|c|}
\hline Temperature $\left({ }^{\mathbf{0}} \mathbf{C}\right)$ & Temperature $\left({ }^{\mathbf{0}} \mathbf{K}\right)$ & $\mathbf{( 1 / T )}$ & $\mathbf{k} / \mathbf{m i n}$ & $\mathbf{l n k}$ \\
\hline 40 & 313 & 0.003195 & 0.0148 & -4.213128 \\
\hline 50 & 323 & 0.003095 & 0.0187 & -3.979231 \\
\hline 60 & 333 & 0.003003 & 0.0193 & -3.947650 \\
\hline
\end{tabular}

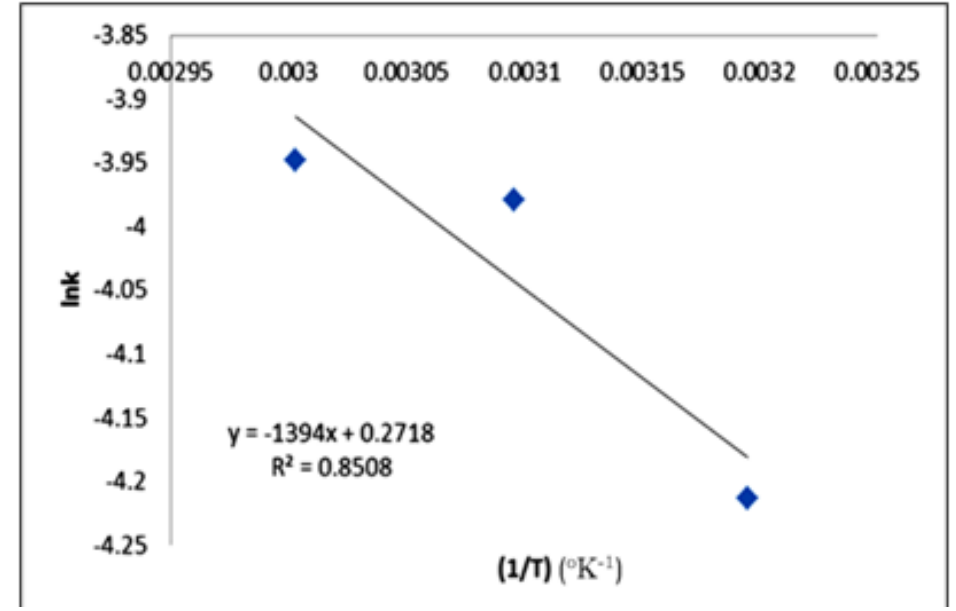

Figure 18

\section{CONCLUSIONS}

The production of the biodiesel from WCO with methanol was carried out with Flyash-KNO3 catalyst in conventional batch reactor. The prepared Catalyst was characterized by FTIR, XRD and SEM. Performance of the prepared catalysts was evaluated by varying the temperature, molar ratios and catalyst loading for the production of biodiesel from WCO. The conversion of WCO increased with increasing the temperatures, molar ratio and catalyst loading. The maximum conversion of $83.4 \%$ WCO was obtained at temperature of $60^{\circ} \mathrm{C}$, molar ratio of 9:1 (methanol to WCO) within 90 min at $1.5 \%$ catalyst loading. The trans-esterification reaction obeys the pseudo first order kinetics and the activation energy are calculated for $\mathrm{KNO}_{3} /$ Fly Ash catalyst: $11.62 \mathrm{~kJ} / \mathrm{mol}$. 


\section{REFERENCES}

1. Heather L. MacLeana, Lester B. Lave, "Evaluating automobile fuel/propulsion system technologies", Progress in Energy and Combustion Science, 29 (2003)1-69.

2. SrinathSuranani, YadagiriMaralla, Shekhar M. Gaikwad, Shirish H. Sonawane, "Process intensification using corning ${ }^{\circledR}$ advanced-flow ${ }^{\mathrm{TM}}$ reactor for continuous flow synthesis of biodiesel from fresh oil and used cooking oil”, Chemical Engineering \& Processing: Process Intensification 126 (2018)62-73.

3. Ying Xia Li and Bing Xue Dong, “Optimization of Lipase-Catalyzed Transesterification of Cotton Seed Oil for Biodiesel Production Using Response Surface Methodology”, Brazilian Archives Of Biology and Technology, 59, (2016)1-7.

4. Brightson, P., et al. "Application of Nanotechnology In Concrete." International Journal of Civil Engineering (IJCE) 2. 2, May 2013, 39-44

5. Deepak Verma, Janmit Raj, Amit Pak, Manish Jain, "A critical review on production of biodiesel from various feed stocks", Journal of Scientific and Innovative Research,5,2,(2016)51-58.

6. Carlos A. Guerrero F., Andres Guerrero-Romero, Fabio E. Sierra, “Biodiesel Production from Waste Cooking Oil”, Biodiesel -Feed stocks and Processing Technologies, Edited by Dr. Margarita Stoytcheva, (2011) 23 -45.

7. George Anastopoulos, YpatiaZannikou, StamoulisStournas, Stamatis Kalligeros, "Transesterification of Vegetable Oils with Ethanol and Characterization of the Key Fuel Properties of Ethyl Esters”, Energies, 2 (2009) 362 -376.

8. James A. Bennett, Karen Wilson, Adam F. Lee, “Catalytic applications of waste derived materials, Journal of Materials Chemistry A, 4, 6 (2016) $3617-3637$.

9. Srikanth, D., et al. "Performance exhaust emissions, and combustion characteristics of cotton seed oil based biodiesel in ceramic coated diesel engine." International Journal of Mechanical Engineering 2.5 (2013): 67-82.

10. M. C. Math, SudheerPrem Kumar, Soma V. Chetty, "Technologies for biodiesel production from used cooking oil - A review”, Energy for Sustainable Development, 14, 4 (2010)339-345.

11. B. Rajam, Ch. Venumadhav, P. S. Saiprasad, Ch. Sailu and V. V. Basavarao, "Thermodynamic parameter Evaluation and Reaction Studies for butanol esterification process in presence of sodium- bentonite catalyst”, Journal of Engineering and Technology, 3 (1) (2015)1-10.

12. Jena, Sandeep Kumar, et al. "Chlorination roasting coupled water leaching process for potash recovery from waste mica scrap using dry marble sludge powder and sodium chloride." International Journal of Minerals, Metallurgy and Materials: 00.

13. RavindraPogaku, JegannathanKenthorai Raman and GujjulaRavikumar, Evaluation of activation energy and thermodynamic properties of enzyme- catalyzed transesterification reactions, Advances in Chemical Engineering and Science, 150-154,2012.

14. Yemelyanova, V. S., et al. "Processing fly ash from the thermal power stations for gas emissions purification from sulfur dioxide." International Journal of Mechanical and Production Engineering Research and Development 9 (2019): 1027-1036.

15. Ahmad A L, YasinN H, Derek C J and Lim J K, Kinetic studies and thermodynamics of oil extraction and transesterification of Chlorella sp. for Biodiesel production, Environmental Technology, Vol.35,2014. 